\title{
The threshold for protective sensation that prevents neuropathic ulceration on the plantar aspect of the foot: a study of leprosy patients in a rural community in India
}

\author{
P. D. MITCHELL \\ Philadelphia Leprosy Hospital, Salur, Vizianagaram District, \\ Andhra Pradesh 532 591, India
}

Accepted for publication 19 February 2001

\begin{abstract}
Summary The protective sensation threshold is an important concept in the prevention of plantar ulceration in leprosy patients. Previous studies have suggested that skin with sensory nerve damage on the plantar aspect of the foot which can still detect the 5.07 Semmes-Weinstein monofilament $(\sim 10 \mathrm{~g})$ is highly unlikely to develop ulceration. While the threshold is thought to be less than the $6 \cdot 10$ filament ( $\sim 75 \mathrm{~g}$ ), no work just testing adjacent to current ulcers has been undertaken to assess this more accurately. This is important, as it has been shown that a significant proportion of healthy individuals who wear sandals or go barefoot in India may fail to detect this 5.07 filament in at least some areas of the sole, especially in older age groups, and in certain cases the 5.46 filament $(\sim 30 \mathrm{~g})$ is the lightest detected. In an attempt to address this problem, a cross-sectional study on 26 current plantar ulcers in male adults with stable neuropathy due to leprosy was carried out in the rural town of Salur, India. It was confirmed that the ability to detect the 5.07 filament $(\sim 10 \mathrm{~g})$ did prevent the development of ulceration while in contrast the ability to detect the 5.46 filament $(\sim 30 \mathrm{~g})$ did not. This suggests that the threshold for protective sensation lies between these two filaments. An approach is suggested which may help to differentiate feet genuinely at risk of ulceration from those merely unable to detect the 5.07 filament on account of thickened skin callus or advancing age.
\end{abstract}

\section{Introduction}

Ulceration on the plantar aspect of the foot is a frequent complication of neuropathy due to leprosy. ${ }^{1-3}$ It is important for clinicians to know when nerve damage has progressed to the point where the skin is at risk of developing ulceration, if subjected to certain insults such as shear stresses from walking. Protective sensation is a term which has been used to describe the level at which the sensibility threshold of the skin to light touch stimuli is still sufficient to prevent the formation of ulcers. ${ }^{4-6}$ Any further impairment in sensibility beyond this level 
means that there is insufficient sensory awareness in the skin to detect the insults which have the potential to lead to significant tissue damage and subsequent ulceration.

While a number of techniques have been used to assess sensibility to light touch stimuli in the skin, ${ }^{7-9}$ Semmes-Weinstein graded nylon monofilaments are known to be a sensitive, reproducible and practical method. ${ }^{10-12}$ These filaments have be used in apparently healthy skin adjacent to ulceration to determine the sensibility in that skin. In criticizing this method, it could be argued that only testing at the ulcer site itself would give the true sensibility, but this is clearly not possible once the ulcer has developed, nor after healing, when thickened scar tissue together with the potential for neurological improvement will complicate interpretation of results. The ideal approach, a large prospective study with frequent testing of locations across the sole to determine sensibility prior to the formation of any ulcers, has yet to be undertaken. However, it has been shown in a cross-sectional study testing adjacent to ulcers that skin which is able to detect the 5.07 filament $(\sim 10 \mathrm{~g})$ is highly unlikely to develop plantar ulceration while skin able to detect the $6 \cdot 10$ filament $(\sim 75 \mathrm{~g})$ is still at risk of ulceration. ${ }^{4}$ It is believed that the threshold of protective sensation for the plantar aspect of the foot must therefore lie somewhere between $10 \mathrm{~g}$ and $75 \mathrm{~g}$, but no studies specifically testing skin adjacent to current ulcers have used a filament between these two to clarify the level further. In many populations this is not actually necessary as the 5.07 filament is suitable for screening for sensory impairment, since it is usually detected by all healthy individuals in communities where shoes are worn. ${ }^{4,13}$ However, recent work in the rural community of Salur in India has shown that a significant proportion of healthy individuals who go barefoot or wear sandals produce thickened callus on the sole of the foot so that certain parts of the sole are unable to detect the 5.07 filament. ${ }^{14}$ Similar findings have been noted in Ethiopia, ${ }^{15}$ so this is clearly not a local phenomenon. Furthermore, it is now known that sensibility thresholds in feet actually increase with age due to physiological deterioration in nerve function, so that many older individuals can no longer feel the 5.07 filament. ${ }^{14,16}$ At Salur all individuals were, however, able to detect the $5 \cdot 46$ filament $(\sim 30 \mathrm{~g})$ at all locations.

In light of these findings, it is necessary to determine if a filament can be identified that will differentiate those at risk of plantar ulceration from those with a higher sensibility threshold merely due to thickened callus or the normal ageing process. As the 5.46 filament lies between the previously used 5.07 and 6.10 filaments, it is interesting to see if it would be a suitable tool. The ability to identify the population at risk would allow more effective targeting of resources, so that only those with sufficient neuropathy to be at risk of complications need receive the extra measures available to minimize the formation of ulcers. While it is appreciated that not all developing regions can afford Semmes-Weinstein monofilaments at present, it is possible that the money saved by better targeting of existing resources may cover the cost of widespread use.

\section{Materials and methods}

All adult male leprosy patients released from treatment between 1983 and 1988 in the town of Salur, Andhra Pradesh State, India were identified. Those from the town who experienced longstanding stable plantar sensory impairment at the time of this study were asked to take part. They were identified as having sensory impairment by present or past plantar ulceration or failure in previous sensation testing using the ball-point pen technique. One hundred percent of these individuals complied, making a patient group of 54 individuals. In an area 
characterized by monsoon and dry seasons, it might be expected that plantar sensation would vary as the skin becomes softened in the wet months and slowly hardens afterwards. ${ }^{17}$ In consequence, a study on the same individuals might yield differing results depending on the season. Again, high temperatures and humidity are thought to alter the properties of the Semmes-Weinstein nylon monofilaments so that they buckle more easily than in cooler, dryer climates, and exert less force. ${ }^{18}$ For ease of comparison with other research, it should be noted that the work was undertaken during the months of November and December, at the end of the monsoon, with high humidity and temperatures typically between $20^{\circ}$ and $30^{\circ} \mathrm{C}$.

The Semmes-Weinstein monofilaments were tested on a Sartorius L2200P top-loading balance to confirm their accuracy. Each filament was tested five times by applying perpendicularly to the balance until bowing, using a technique described elsewhere, ${ }^{11,18}$ and the mean force calculated. The diameters were also checked using a binocular light microscope linked by a video camera to an RGB software package and compared with past work. The filament index numbers ( $\log _{10} \times$ force required to bow the filament) were then confirmed by consulting past research. ${ }^{11,18}$ The mean force exerted by the filament of index 4.56 was $3.1 \mathrm{~g}$, by the 5.07 was $8.0 \mathrm{~g}$, by the 5.46 was $29.5 \mathrm{~g}$ and by the 6.45 was $203 \mathrm{~g}$. It is well known that monofilaments do not exert exactly the same force in practice as recorded by any of the manufacturers, as they are not made to exacting standards ${ }^{19}$ to make them more affordable. Variation tends to become more obvious as the index numbers become larger, and so the filaments thicker. The values listed here are comparable with past studies of the forces exerted by these nylon monofilaments. ${ }^{11,18}$ In consequence, here we refer to the monofilament by its index number rather than by an estimation of the force it exerts.

All the patients were examined by the same clinician to avoid inter-observer variation. Sensory function was assessed on the apparently healthy skin immediately surrounding each ulcer. Skin with scarring, excess callus, granulation tissue or necrosis was avoided. The tests, outlined in detail elsewhere, ${ }^{11,18}$ took place in quiet surroundings and were explained to each participant who then looked away from his feet. Each of the Semmes-Weinstein monofilaments with index $4 \cdot 56,5 \cdot 07,5 \cdot 46$ and 6.45 was applied in a concealed and random manner.

\section{Results}

Of the 54 individuals in this patient group, 18 (33\%) had current plantar ulceration, $26(48 \%)$ had no current ulcers but had done in the past and the remaining $10(19 \%)$ had never had ulcers. Those with current ulceration were entered into the study. Details of their footwear use, class of occupation and age are shown in Table 1. Twenty-six ulcers were noted on the 18 individuals, each with both feet remaining (Figure 1). Sensation in apparently normal skin immediately adjacent to these ulcers was tested with the range of monofilaments. No individual was able to feel either the filaments with index of 4.56 or 5.07 in the surrounding skin. However, the 5.46 was felt around seven ulcers (27\%) and in those unable to feel this, the 6.45 was noted around four ulcers $(15 \%)$. The skin surrounding the remaining 15 ulcers was unable to detect any of the filaments (Table 2).

\section{Discussion}

In this community protective sensation was shown to be present where skin could detect a 5.07 monofilament in $100 \%$ of cases. Past research that tested skin adjacent to current ulcers 
Table 1. Summary of the study population for age, occupation and footwear $(n=18)$

\begin{tabular}{|c|c|c|c|c|}
\hline Age range (years) & $30-39$ & $40-49$ & $50-59$ & $60-69$ \\
\hline & $6(33 \%)$ & $6(33 \%)$ & $2(11 \%)$ & $4(23 \%)$ \\
\hline Occupation & \multicolumn{2}{|c|}{$\begin{array}{l}\text { Light work (office or shop) } \\
12(67 \%)\end{array}$} & \multicolumn{2}{|c|}{$\begin{array}{l}\text { Heavy work (labourer or farmer) } \\
\quad 6(33 \%)\end{array}$} \\
\hline $\begin{array}{l}\text { Use of footwear } \\
\text { At work } \\
\text { At home }\end{array}$ & $\begin{array}{c}\text { None } \\
6(33 \%) \\
14(78 \%)\end{array}$ & $\begin{array}{l}\text { Sandals } \\
3(17 \%) \\
0(0 \%)\end{array}$ & $\begin{array}{c}M C R \\
8(44 \%) \\
4(22 \%)\end{array}$ & $\begin{array}{l}\text { Shoes } \\
1(6 \%) \\
0(0 \%)\end{array}$ \\
\hline
\end{tabular}

has also found skin able to detect the 5.07 filament to be free from ulceration. ${ }^{4}$ This agreement between research in the developed and developing world suggests that it may be related to the anatomy and neurophysiology of the skin over the human foot and be independent of environmental factors. In some past studies of protective sensation, the site of sensory testing remained identical regardless of the location of ulceration ${ }^{5}$ and an individual with an ulcer at one site may have had normal sensation at the location where sensation was actually tested. The design of the study presented here has ensured that it is the

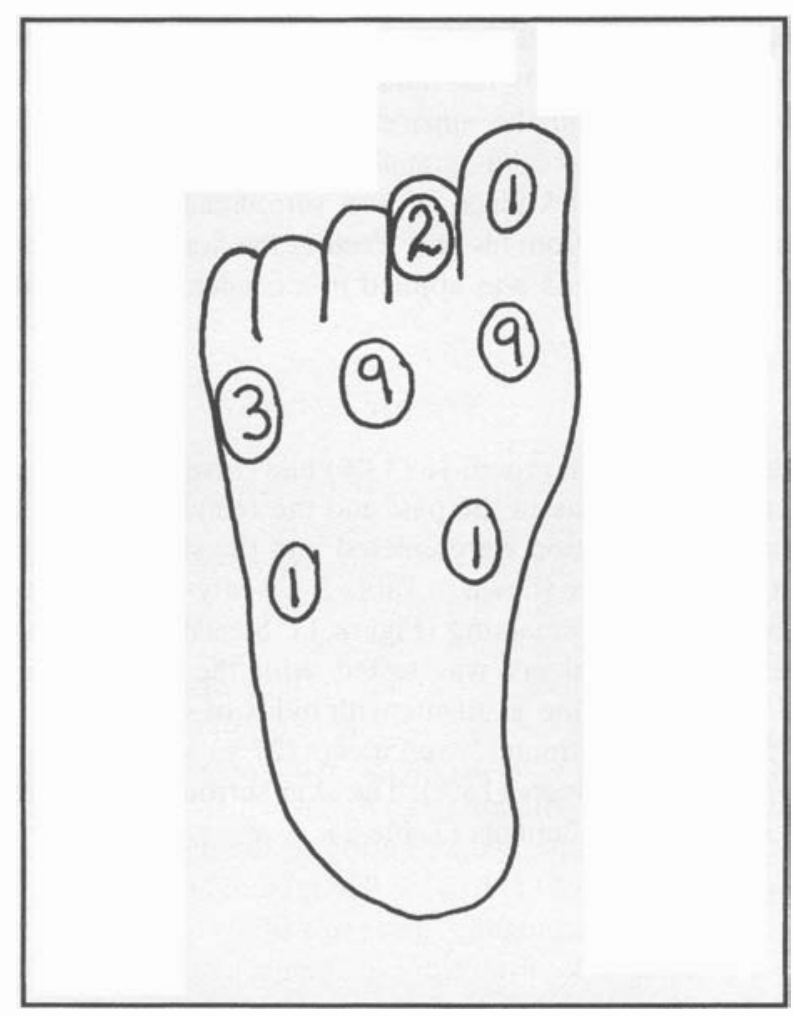

Figure 1. Location of current ulcers $(n=26)$ 
Table 2. Best sensation in skin surrounding current ulcers

\begin{tabular}{llcccc}
\hline & & & \multicolumn{2}{c}{ Lightest filament detected } & \\
& 4.56 & 5.07 & 5.46 & 6.45 & None \\
\hline $\begin{array}{l}\text { No. of ulcers } \\
(n=26)\end{array}$ & 0 & 0 & $7(27 \%)$ & $4(15 \%)$ & $15(58 \%)$ \\
\hline
\end{tabular}

apparently healthy skin immediately adjacent to the ulcer which is tested, allowing a more representative assessment of sensibility of the skin in the area of the ulcer. Other research has tested sensation at the site of ulcers but also amalgamated data from tests at the site of ulcer scars, where previous ulcers have healed. ${ }^{6}$ This means that the data have to viewed with caution, as there is no way of knowing if sensibility at the time of testing is the same as when the ulcer originally formed. It is quite possible that the nerve damage may have either progressed or healed with treatment since the ulcer was present, so that it is impossible to determine from this data the degree of sensation loss required before an ulcer can develop.

In this study, ulcers were noted in areas of callus skin able to sense the 5.46 filament $(\sim 30 \mathrm{~g})$. Previous work has determined that skin able to detect the $6 \cdot 10$ filament $(\sim 75 \mathrm{~g})$ but not the $5.07(\sim 10 \mathrm{~g})$ is at risk of developing ulceration but no work just testing adjacent to current ulcers has been performed to determine more exactly where the level of protective sensation actually lies. For this population, we have found that the threshold of protective sensation lies between the force applied by the 5.07 and 5.46 filaments. In populations where everyone can feel the 5.07 filament, especially where wearing shoes in common, then it seems reasonable to continue to use this filament as a tool to identify those at risk of developing plantar ulcers.

However, study of light touch sensibility thresholds in healthy individuals from some rural areas of India has shown that many of those who go barefoot or wear sandals for only part of the day are unable to detect the 5.07 filament, especially in older age groups. ${ }^{14}$ They are, nevertheless, all able to detect the stiffer 5.46 filament. Similar research in Ethiopia has also demonstrated that the feet of many individuals are unable to detect the 5.07 filament, ${ }^{15}$ so it is clearly not a localized phenomenon. This leaves the clinician managing the care of leprosy patients in some rural areas with a difficult dilemma. If all those who fail to detect the 5.07 filament are regarded as at risk of developing plantar ulcers, then it is likely that all those genuinely at risk of developing ulcers will have been identified, and can be managed appropriately. However, together with those genuinely at risk, a significant proportion of patients without nerve damage from leprosy may also be included if they are unable to detect the filament on account of thickened callous skin or normal age-dependent deterioration in sensibility threshold. It seems that testing using the 5.07 filament in this community would have very high sensitivity but only low specificity. While this might be the safest approach, it would flood clinicians with extra patients to assess, when so many clinics and hospitals are already overstretched. An alternative would be to use the 5.46 filament. This is felt by all individuals of all ages in all areas of the foot, so that it would ensure that no normal feet were included in the at risk group. Unfortunately, using this filament would mean that a proportion of patients who are at genuine risk of developing plantar ulceration would not be identified, $27 \%$ in this study. In consequence, the 5.46 filament would have very high specificity but only moderate sensitivity. 
A further interesting finding was that leprosy patients may develop plantar ulceration in skin only able to detect the 5.46 filament while healthy controls never do, even in areas of the foot with apparently the same sensibility threshold. One possible explanation is that the thickened, keratinized sole of a hard working, healthy foot impairs the ability of sensory receptors to detect fine touch stimuli such as the lighter monofilaments. However, deeper in the sole there remains the normal number of functioning sensory receptors. It is known that shearing stresses responsible for much ulceration act not just on the skin surface, where monofilaments are applied, but also deeper in the dermis and between tissue planes. ${ }^{20}$ It is reasonable to presume that these deeper receptors in healthy individuals would detect early tissue damage quickly and lead to appropriate action to reduce this insult to the foot, perhaps by resting or modifying walking style. Patients with neuropathy, however, may have impaired function in both the most superficial and also deeper receptors. In consequence they will not detect friction stresses in deeper tissues and trauma may result, of ten developing into an ulcer if appropriate measures are not taken. It seems that while Semmes-Weinstein monofilaments are a good test for light touch sensation, they do have limitations in their ability to assess protective sensation in the foot. The monofilaments are not designed to assess sensibility to shear stress in the foot and it is this insult which is believed to be responsible for the majority of plantar ulcers. In consequence, a patient who fails to detect the 5.07 filament may not actually be at risk of developing ulcers if they can still detect shear stress adequately.

In the absence of a cheap and easy to use method of testing sensibility to shear stress in the foot, an alternative method of differentiating between these two groups must be found. One approach to this is to use common sense in conjunction with clinical assessment and these suggested guidelines might be found useful.

1. All those patients who can detect the 5.07 filament appear to be safe from developing plantar ulcers.

2. All those patients who fail to detect the $5 \cdot 46$ filament should definitely be regarded as at risk of ulceration.

3. Those who cannot detect the 5.07 filament but can detect the 5.46 filament should be suspected of being at risk of plantar ulcers if:

a) they regularly wear shoes;

b) or they have impaired sensation compared with the same area on the other foot;

c) or have deteriorating sensation even if still able to detect the 5.46 filament.

4. If the sensation threshold for callous skin remains stable, comparable with the same location on the other foot and $\leq 5.46$ filament, this may well be normal for them if they do not wear shoes or are of advancing age. This does not necessarily imply that they are at risk of ulceration.

Using this guide may help workers in rural developing world communities to differentiate those patients genuinely at risk from plantar ulceration from those who fail the 5.07 filament test due to thickened callus or advancing age. This study has not been designed to identify which sites on the foot to test, but rather which filament to use in testing and how to interpret the results. There is great variability in the locations tested on the sole of the foot, from a thorough 11 or 12 site approach. ${ }^{14,21,22}$ to a less time consuming technique of as few as perhaps three to five sites. ${ }^{5,23,24}$ However, it has yet to be determined in a prospective trial just which locations need to be tested in order to safely identify early sensory impairment. While one is awaited it might be prudent to test all those sites known to develop ulcers and to do this does require an 11 or 12 location technique. 
An impartial prospective study of sufficient size in a comparable rural area would be useful firstly to confirm if these findings are a local phenomenon or representative of the wider population, secondly to assess the effectiveness of these suggested guidelines and thirdly to identify which locations on the foot to test. If that study were to validate the findings presented here, then companies manufacturing the Semmes-Weinstein monofilaments might choose to include the 5.46 filament in one of their standard sets and so allow its application in those communities in which shoes are rarely worn.

\section{Acknowledgements}

Many thanks to The Leprosy Mission, LEPRA and the St Francis Leprosy Guild for contributing towards the expenses of this research. I am also grateful to Dr Rajan Babu, Ms Catherine Benbow (OT) and to Mr E. J. Devasahayam (LCS) for valuable assistance in formulating and undertaking the study.

\section{References}

1 Andersen JG. Plantar ulcers in leprosy. Lepr Rev, 1961; 32: 16-27.

2 Kazen RO. Management of plantar ulcers in leprosy. Lepr Rev, 1999; 70: 63-69.

${ }^{3}$ Ross WF. Etiology and treatment of plantar ulcers. Lepr Rev, 1962; 33: 25-40.

${ }^{4}$ Birke JA, Sims DS. Plantar sensory threshold in the ulcerative foot. Lepr Rev, 1986; 57: 261-267.

5 Hammond CJ, Klenerman P. Protective sensation in the foot in leprosy. LeprRev, 1988; 59: 347-354.

6 Malaviya GN, Hussain S, Mishra B et al. Protective sensibility - its monofilament nylon threshold equivalents in leprosy patients. Ind J Lepr, 1997; 69: 149-158.

7 Narayanakumar TS, Subramanian A, Manivannan K. A method for texture discrimination in the sole of the foot. A preliminary communication. Lepr Rev, 1995; 66: 165-168.

8 Srinivasan H, Stumpe B. Leprosy diagnosis: a device for testing the thermal sensibility of skin lesions in the field. Bull World Health Org, 1989; 67: 635-641.

9 Van Brakel WH, Shute J, Dix on JA, Arzet H. Evaluation of sensibility in leprosy -comparison of various clinical methods. Lepr Rev, 1994; 65: 106-121.

10 Anderson AM, Croft RP. Reliability of Semmes-Weinstein monofilament and ballpoint sensory testing, and voluntary muscle testing in Bangladesh. Lepr Rev, 1999; 70: 305-313.

11 Bell-Krotoski J, Tomancik E. The repeatability of testing with Semmes-Weinstein monofilaments. J Hand Surg, 1987; 12A: 155-161.

12 Van Brakel, WH, Khawas IB, Gurung KS et al. Intra- and inter-tester reliability of sensibility testing in leprosy. Int J Lepr, 1996; 64: 287-298.

13 Stratford CJ, Owen BM. The effect of footwear on sensory testing in leprosy. Lepr Rev, 1994; 65: 58-65.

14 Mitchell PD, Mitchell TN. The age-dependent deterioration in light touch sensation on the plantar aspect of the foot in a rural community in India: implications when screening for sensory impairment. Lepr Rev, 2000; 71: $169-178$.

15 Currie H, Byass P. Footsole sensation in normal subjects in Ethiopia. Int J Lepr, 1993; 61: 158A.

16 Anderson AM, van Brakel WH. Age specific thresholds for sensibility testing with monofilaments in a Nepali population. Int J Lepr, 1998; 66: 158 (abstract).

17 McAuley DM, Ewing PA, Devasundaram JK. Effect of hand soaking on sensory testing. Int J Lepr, 1993; 61: $16-19$.

18 Levin S, Pearshall G, Ruderman R. Von Frey's method of measuring pressure sensibility in the hand: an engineering analysis of the Weinstein-Semmes pressure aesthesiometer. J Hand Surg, 1978; 3: 211-216.

19 Bell-Krotoski J, Coor, V. Semmes-Weinstein monofilament detection thresholds: a comparative study. Int J Lepr, 1993; 61: 146.

20 Bauman JH, Girling JP, Brand PW. Plantar pressures and trophic ulceration. J Bone Joint Surg, 1963; 45B: 652673.

${ }^{21}$ Richardus JH, Finlay KM, Croft RP, Smith WCS. Nerve function impairment in leprosy at diagnosis and at completion of MDT: a retrospective cohort study of 786 patients in Bangladesh. Lepr Rev, 1996; 67: 297-305. 
${ }^{22}$ Croft RP, Richardus JH, Nicholls PG, Smith WCS. Nerve function impairment in leprosy: design, methodology and intake status of a prospective cohort study of 2664 new leprosy cases in Bangladesh (The Bangladesh Acute Nerve Damage Study). Lepr Rev, 1999; 70: 140-159.

23 Srinivasan H. Prevention of disabilities in patients with leprosy. World Health Organisation, Geneva, 1993 , p. 51.

24 Kets CM, van Leerdam ME, van Brakel WH et al. Reference values for touch sensibility thresholds in healthy Nepalese volunteers. Lepr Rev, 1996; 67: 28-38. 